\title{
Metabolic syndrome in the elderly living in marginal peri-urban communities in Quito, Ecuador
}

Fernando Sempértegui ${ }^{1,9}$, Bertha Estrella ${ }^{1}$, Katherine L Tucker ${ }^{2,3}$, Davidson H Hamer $^{3,4,5}$, Ximena Narvaez ${ }^{1}$, Mercy Sempértegui ${ }^{1}$, Jeffrey K Griffiths ${ }^{3,7,8}$, Sabrina E Noel ${ }^{2}$, Gerard E Dallal ${ }^{2,3}$, Jacob Selhub ${ }^{2,3}$ and Simin N Meydani ${ }^{2,3,6, *}$ ${ }^{1}$ Corporación Ecuatoriana de Biotecnología, Quito, Ecuador: ${ }^{2} J e a n$ Mayer USDA Human Nutrition Research Center on Aging, Tufts University, 711 Washington Street, Boston, MA 02111 , USA: ${ }^{3}$ Tufts University Friedman School of Nutrition Science and Policy, Boston, MA, USA: ${ }^{4}$ Center for Global Health and Development, Boston University School of Public Health, Boston, MA, USA: ${ }^{5}$ Section of Infectious Diseases, Department of Medicine, Boston University School of Medicine, Boston, MA, USA: 'Department of Pathology, Sackler School of Graduate Sciences, Tufts University, Boston, MA, USA: ${ }^{7}$ Department of Public Health and Family Medicine, Tufts University School of Medicine, Boston MA, USA: ${ }^{8}$ Department of Civil and Environmental Engineering, Tufts University School of Engineering, Medford, MA, USA: ${ }^{9}$ Medical School, Central University of Ecuador, Ecuador

\section{Submitted 14 December 2009: Accepted 7 August 2010: First published online 19 October 2010}

\begin{abstract}
Objective: The proportion of the Latin American population aged $>60$ years is expected to double during the next few decades. Metabolic syndrome (MetS) is associated with high morbidity and mortality worldwide. However, little is known about MetS in Latin America in general, and in Ecuador in particular. The present study aimed to examine the prevalence of MetS and its association with blood micronutrient, homocysteine (Hcy) and C-reactive protein (CRP) concentrations in the elderly living in a low-income urban area.

Design: We performed a cross-sectional study. MetS, using the International Diabetes Federation definition, dietary intake and plasma micronutrient, CRP and Hcy concentrations were assessed.

Subjects: A total of 352 elderly ( $\geq 65$ years) Ecuadorians.

Setting: Quito, Ecuador.

Results: MetS was prevalent (40\%) - considerably more so among women (81\%) than men $\left(19 \% ; \chi^{2}=32 \cdot 6, P<0 \cdot 0001\right)$. Further, $53 \%$ of those without MetS exhibited two or more of its components. Micronutrient deficiencies were prevalent, including those of vitamin $\mathrm{C}$, zinc, vitamin $\mathrm{B}_{12}$ and folate. Vitamin $\mathrm{C}$ and $\mathrm{E}$ concentrations were inversely $(\mathrm{OR}=0 \cdot 78,95 \% \mathrm{CI} 0 \cdot 71,0 \cdot 86$; OR $=0 \cdot 16,95 \% \mathrm{CI}$ $0 \cdot 03,0 \cdot 81$, respectively) and CRP $(\mathrm{OR}=1 \cdot 79,95 \%$ CI $1 \cdot 04,3 \cdot 06)$ was positively associated with MetS.

Conclusions: The coexistence of MetS with micronutrient deficiencies suggests that elderly Ecuadorians suffer from the double burden of diseases that are increasingly being observed in less developed countries. More research is needed to determine the causal factors, but results presented suggest that these older adults would benefit from interventions to reduce the risk factors for MetS, in particular higher consumption of micronutrient-rich foods.
\end{abstract}

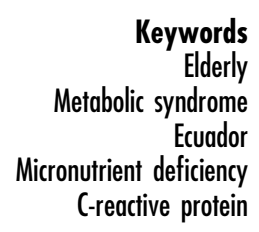

The number of older persons is projected to more than double worldwide over the next half century ${ }^{(1)}$. Most of this elderly population will be living in developing countries, which are the least prepared to deal with the challenges of an ageing society ${ }^{(2)}$. According to the estimates of the United Nations, the population of Latin American and Caribbean adults aged $>60$ years will almost double, from about 59 million $(10.0 \%$ of the total population) in 2010 to 101 million $(15 \cdot 1 \%$ of the total population) in $2025^{(3)}$. Currently, those aged $>60$ years in
Ecuador represent 9.5\% of the population (1303000 inhabitants), and this is predicted to rise to $14 \cdot 1 \%$ (2 262000 inhabitants) by $2025^{(3)}$. A recent report from the Pan American Health Organization and Merck Institute of Aging and Health calls for increased surveillance to identify the extent and causes of morbidity and mortality in older adults ${ }^{(4)}$.

Ecuador, like much of Latin America, has not experienced improvements in living standards to the same degree as most developed nations. Older adults in Latin 
American countries are likely to have comparatively more diseases, greater disability and fewer resources for their health-care needs. Although developed nations have gradually increased their national health resources for older adults, few of the limited health resources of the less developed countries have been devoted to their ageing populations. Since older adults face high burdens of disease and disability, this threatens to increase the strains on the limited health-care resources of their countries.

Metabolic syndrome (MetS) is characterized by disturbed glucose and insulin metabolism, central adiposity, dyslipidaemia and high blood pressure (BP), and is associated with type 2 diabetes, CVD and mortality ${ }^{(5)}$. Although the aetiology of MetS has not been fully elucidated, available evidence suggests that it is the result of a complex interaction between genetic, metabolic and environmental factors ${ }^{(6)}$. Nutritional factors are the most prominent environmental influences, including obesity, dietary glycaemic index $(\mathrm{GI})^{(7)}$, fruit and vegetable intake ${ }^{(8)}$, total and type of fat intake ${ }^{(9,10)}$, antioxidant nutrients ${ }^{(11)}$, B vitamins and dairy products ${ }^{(12)}$. Intake of high-GI carbohydrates was positively associated with insulin resistance and prevalence of the MetS in participants of the Framingham Offspring Study ${ }^{(7)}$. Higher intake of fruit and vegetables was shown to be inversely associated with plasma C-reactive protein (CRP) concentrations, as well as likelihood of having the MetS in a cross-sectional study of 486 Iranian women ${ }^{(8)}$. Data from the Third National Health and Nutrition Examination Survey (NHANES III) showed that participants with MetS had significantly lower circulating concentrations of vitamin $\mathrm{C}$, carotenoids and vitamin $\mathrm{E}^{(11)}$. High total fat intake, mainly that of saturated fat, has been linked to lower insulin sensitivity, whereas increased proportions of MUFA improved insulin sensitivity in adults $^{(9)}$. Higher relative intake of vegetable oils and lower intake of foods containing saturated fat at 50 years of age were protective against developing sustained hypertension 20 years later ${ }^{(10)}$. In a recent study, ferritin and transferrin concentrations were shown to be associated with MetS abnormalities $^{(13)}$.

Our previous preliminary work in elderly Ecuadorians living in poor peri-urban communities showed a high prevalence of elevated waist circumference and low HDL cholesterol concentration, both components of MetS ${ }^{(14)}$. Energy intake was mainly dependent on high carbohydrate consumption ( $76.7 \%$ of total energy). Furthermore, a high prevalence of several micronutrient deficiencies was found ${ }^{(14)}$. CVD is now the primary cause of morbidity and mortality in Ecuadorian elders ${ }^{(15)}$. These findings suggest that the increasing elderly population of Ecuador is at risk for MetS, although no specific information is available for them. Given that the low status of micronutrients such as antioxidants and $\mathrm{B}$ vitamins has been suggested to be associated with increased risk for MetS, the present study was conducted using a much larger sample size than that in our preliminary study to determine the prevalence of MetS in elderly Ecuadorians and its association with blood micronutrient concentrations.

In our previous study, $25 \%$ of sampled older adults showed blood homocysteine (Hcy) concentration above the upper limit ${ }^{(14)}$. Markers of low-grade inflammation, such as $\mathrm{CRP}^{(16)}$ and $\mathrm{Hcy}^{(17)}$, have been shown to be associated with CVD. Therefore, we also aimed to determine the association of these inflammation markers with micronutrient concentrations and with MetS. The present study presents the first report on MetS prevalence in elders living in the poor peri-urban communities of Quito, Ecuador and its relationship to blood micronutrient concentrations and inflammation markers.

\section{Experimental methods}

\section{Study site and population}

This cross-sectional study was conducted from September 2003 to December 2004 in three adjacent poor peri-urban neighbourhoods in north-western Quito $(2800 \mathrm{~m}$ above the sea level). The study area had an estimated population of 13000 and, based on electoral results, 5\% were above the age of 65 years. The neighbourhoods are located on a hillside and are structurally similar, with one main paved road and electricity present in all homes. According to the baseline information collected during the screening phase, just over half of the households had a municipal source of potable water (52\%) and sewerage $(62 \%)$. The inhabitants were primarily poor immigrants from small cities and rural areas of Ecuador. Their mean monthly income was US\$54, which is $<50 \%$ of the basic income in Ecuador, and $>40 \%$ of the elderly individuals were illiterate. The living conditions of this population are similar to those of the poor urban slums of other Andean countries such as Peru and Bolivia.

\section{Screening and enrolment}

To identify the eligible participants, we carried out a census in the three neighbourhoods. Eligibility criteria included age $\geq 65$ years, mental competence and willingness to provide written informed consent. Age was verified via national identification cards. Mental competence was determined with a variation of the Mini Mental State Examination (MMSE) that has been used in several countries previously, including Spain and Guatemala ${ }^{(18)}$. We identified and provided detailed information about the study to 413 potential participants, who were asked for consent to participate. If the individual was illiterate, the form was read to them in the presence of a literate family member. Of the 413 elderly invited, 352 (85\%) agreed to participate via witnessed informed consent. The Ethics Committees of the Corporación Ecuatoriana de Biotecnología and the Tufts-New England Medical Center Institutional Review Board approved the study protocol and informed consent. 


\section{Study procedures}

The participants were asked to visit one of the three field stations centrally located in each neighbourhood (a church, a school or a communitarian house). Two physicians and two nurses collected anthropometric data and blood samples. Before the study, all study personnel received training and conducted data collection on the same test participants to check for inter-observer differences. Two nutritionists collected dietary data through household visits. Previously, they also administered the dietary survey jointly to other older adults to close the inter-observer differences.

\section{Anthropometry}

Anthropometric measurements were obtained using methods described by Gross ${ }^{(18)}$ and included weight, height, knee height and waist circumference. Weight was recorded to the nearest $0 \cdot 1 \mathrm{~kg}$ using a Detecto scale (Detecto ${ }^{\circledR}$, Webb City, MO, USA). The participants were asked to wear the least amount of clothing possible. Height was measured to the nearest $0 \cdot 1 \mathrm{~cm}$, using a steel fibreglass measuring tape affixed to a wooden rod, with a sturdy straight edge used as a headpiece. We also measured knee height to the nearest $0 \cdot 1 \mathrm{~cm}$, using a knee-height anthropometer ${ }^{(19)}$. This measurement can be used to estimate standing height for older participants who are unable to stand erect, using published equations ${ }^{(19)}$. Waist circumference was measured between the border of the right anterior superior iliac crest and the umbilicus, and was recorded to the nearest $0 \cdot 1 \mathrm{~cm}$ using a fibreglass measuring tape. BMI was calculated as weight in kilograms divided by the square of height in metres $\left(\mathrm{kg} / \mathrm{m}^{2}\right)^{(20)}$. The following BMI classifications were used: underweight (BMI $<20 \mathrm{~kg} / \mathrm{m}^{2}$ ), normal weight (BMI 20-24.9 kg/m²), overweight (BMI $25-29 \cdot 9 \mathrm{~kg} / \mathrm{m}^{2}$ ) and obese $\left(\mathrm{BMI} \geq 30 \mathrm{~kg} / \mathrm{m}^{2}\right)$. Elevated waist circumference was classified using the International Diabetes Federation (IDF) values: men $>90 \mathrm{~cm}$, women $>80 \mathrm{~cm}^{(21)}$.

\section{Blood pressure}

Systolic and diastolic BP were measured in $\mathrm{mmHg}$ by detection of Korotkoff sounds, using a conventional certified sphygmomanometer (CE 0483; Riester, Jungingen, Germany). Right arm measurements were obtained while seated, after resting for at least $15 \mathrm{~min}$. Participants with values $>130 \mathrm{~mm} \mathrm{Hg}$ for systolic or $>85 \mathrm{~mm} \mathrm{Hg}$ for diastolic BP were classified as having high $\mathrm{BP}^{(22)}$.

\section{Laboratory procedures}

Blood samples were obtained at the field stations. A $10 \mathrm{ml}$ venous blood sample was drawn after an overnight fast, into an EDTA-treated tube and a tube without anticoagulant. Samples were immediately transported to the laboratory and centrifuged. Plasma samples for vitamin C were promptly deproteinized using perchloric acid and
EDTA. Serum or plasma was collected in plastic tubes, frozen at $-20^{\circ} \mathrm{C}$, and transported to Boston for micronutrient analysis according to standard procedures at the Nutritional Evaluation Laboratory of the Jean Mayer USDA Human Nutrition Research Center on Aging at Tufts University as described previously ${ }^{(23)}$.

Total plasma Hcy was determined by a method derived from Araki and Sako ${ }^{(24)}$. Controls included pooled plasma samples spiked with different amounts of cysteine and Hcy. The CV for this assay in our laboratory is $7 \cdot 8 \%$. A cut-off point of $>15 \mathrm{nmol} / \mathrm{ml}^{(25)}$ was considered as high Hcy concentration.

CRP was measured in serum, using an immunoturbidimetric reaction in a Cobas Fara II Centrifugal Analyzer with DiaSorin CRP SPQ Test System Antibody Reagent Set II (Item no. 86083, Document AM-0039 (rev 8.27.90); Stillwater, MN, USA). A cut-off point of $>3 \mathrm{mg} / 1$ was considered as high CRP concentration ${ }^{(26,27)}$.

Chemical analyses for fasting glucose, TAG, LDL and HDL cholesterol were assessed in Quito, using a conventional autoanalyser (HITACHI 911, Roche, Germany). Daily quality control of the precision of the equipment was determined using the Westgard multi-rules ${ }^{(28)}$.

\section{Classification of metabolic syndrome}

We used the MetS definition of the IDF and also report the prevalence of MetS using the Adult Treatment Panel III (ATP III) definition ${ }^{(29)}$. The IDF definition ${ }^{(21)}$ requires participants to have central obesity defined by ethnic and sex-specific waist circumference cut-points (men $>90 \mathrm{~cm}$, women $>80 \mathrm{~cm}$ ), plus two of the four other components (elevated TAG $(>1.7 \mathrm{mmol} / 1$ or $>150 \mathrm{mg} / \mathrm{dl})$, elevated BP (systolic BP $\geq 130 \mathrm{~mm} \mathrm{Hg}$ or diastolic $\mathrm{BP} \geq 85 \mathrm{~mm} \mathrm{Hg}$ ), elevated fasting blood glucose $(\geq 5.6 \mathrm{mmol} / \mathrm{l}$ or $\geq 100 \mathrm{mg} / \mathrm{dl}$ ) and low HDL cholesterol $(<1.03 \mathrm{mmol} / \mathrm{l}$ or $<40 \mathrm{mg} / \mathrm{dl}$ for men or $<1.30 \mathrm{mmol} / 1$ or $<50 \mathrm{mg} /$ dl for women $)^{(21)}$. The ATP III definition requires the presence of three or more of the following criteria: (i) elevated waist circumference $(>102 \mathrm{~cm}$ for men and $>88 \mathrm{~cm}$ for women); (ii) elevated TAG $(>1.7 \mathrm{mmol} / 1$ or $\geq 150 \mathrm{mg} / \mathrm{dl})$; (iii) low HDL cholesterol $(<1.03 \mathrm{mmol} / \mathrm{l}$ or $<40 \mathrm{mg} / \mathrm{dl}$ for men and $<1.30 \mathrm{mmol} / 1$ or $<50 \mathrm{mg} / \mathrm{dl}$ for women); (iv) elevated BP (systolic $\mathrm{BP} \geq 130 \mathrm{~mm} \mathrm{Hg}$ or diastolic $\mathrm{BP} \geq 85 \mathrm{~mm} \mathrm{Hg}$ ); and (v) elevated fasting glucose ( $\geq 6 \cdot 1 \mathrm{mmol} / 1$ or $\geq 110 \mathrm{mg} / \mathrm{dl}$ ).

\section{Definitions of micronutrient deficiencies}

The cut-off points for plasma vitamin inadequacies were defined as follows: vitamin $\mathrm{A} \leq 30 \mu \mathrm{g} / \mathrm{dl}^{(30)}$, pyridoxal phosphate $\quad(\mathrm{PLP}) \leq 30 \mathrm{nmol} / \mathrm{l}^{(14,31,32)}$, vitamin $\mathrm{B}_{12} \leq$ $250 \mathrm{pg} / \mathrm{ml}^{(33)}$, folate $\leq 5 \mathrm{ng} / \mathrm{ml}^{(14,34)}$, vitamin $\mathrm{C} \leq 0 \cdot 2 \mathrm{mg} /$ $\mathrm{dl}^{(30)}$, vitamin $\mathrm{E} \leq 500 \mu \mathrm{g} / \mathrm{dl}^{(35)}$ and vitamin $\mathrm{D} \leq 25 \mathrm{ng} / \mathrm{ml}$ for mild deficiency and $\leq 10 \mathrm{ng} / \mathrm{ml}$ for severe deficiency $^{(30)}$. For mineral plasma inadequacies, the cut-off points were: zinc $\leq 70 \mu \mathrm{g} / \mathrm{dl}^{(30)}$, copper $\leq 85 \mu \mathrm{g} / \mathrm{dl}^{(30)}$, iron $\leq 65 \mu \mathrm{g} / \mathrm{dl}$ for men and $\leq 50 \mu \mathrm{g} / \mathrm{dl}$ for women ${ }^{(30)}$ and calcium $\leq 8.6 \mathrm{mg} / \mathrm{dl}^{(30)}$. 


\section{Dietary intake analysis}

Individual dietary intake was estimated with a modified $24 \mathrm{~h}$ recall or weighing $\operatorname{method}^{(36)}$, as described previously $^{(14)}$. Dietary recall questionnaires were applied two times with each participant, on different working days within a week. Briefly, the interview was carried out in each household, and each participant was given an explanation on the importance of answering as truthfully and accurately as possible. In order to help the participant recall the previous day, we asked him or her about his or her activities, such as the time of awakening, daytime activities and when he or she went to bed. This approach helped the participants to remember the foods ingested. During the interview, the amounts of food consumed were verified by asking the participant the size of the household measures used to prepare the consumed food. More details for this dietary method have been published ${ }^{(14)}$. The most experienced observer performed quality control with a thorough review of all recalls to ensure consistency of the data. Two independent data entry staff entered the data into a pre-specified Excel spreadsheet. These data were sent to Tufts University, where they were linked to the USDA (US Department of Agriculture) nutrient database, with the addition of food codes for specific Latin American Foods ${ }^{(37)}$. Foods not included in this file were coded according to the Ecuadorian Table of Foods ${ }^{(38)}$. The $2 \mathrm{~d}$ of dietary measures were averaged to obtain the most stable measure for each individual. The intra- to inter-person variance for the nutrient intakes was also calculated and used in evaluating correlations between nutrient intakes and blood concentrations.

\section{Statistical metbods}

Data entry and management were carried out using Epi-Info software, version 6.04d (Centres for Disease Control and Prevention, Atlanta, GA, USA). Statistical analyses were performed using the Statistical Package for Social Sciences statistical software package version 11.5 (Lead Technologies Inc., SPSS Inc., Chicago, IL, USA). The prevalence of MetS and of its components was calculated overall and by sex. We also calculated the frequency of MetS components in participants with and without MetS syndrome. Differences in means and percentages by sex, and between participants with or without MetS, were evaluated by the Student's $t$ and $\chi^{2}$ tests, respectively.

Multiple logistic regression models, also controlling for age and sex, were fitted to determine whether selected blood micronutrient status, high Hcy or high CRP (as binary variables) were associated with the presence of MetS.

Regression analysis was used to assess associations between blood measures and the mean of the two dietary recalls. Day-to-day within-person variation in the reference method (mean of the two $24 \mathrm{~h}$ dietary recalls) can attenuate the correlations between nutrient intakes derived from dietary recalls and serum measures. The intra- to interperson variance for the nutrient intakes, as estimated by the two $24 \mathrm{~h}$ dietary recalls, was also calculated and reviewed. The formula used to calculate the de-attenuated regression coefficient is $b_{t}=b_{0}\left(1+\operatorname{intra}_{x} /\right.$ inter $\left._{x} / n_{x}\right)$, where $b_{O}$ is the observed coefficient (slope) of the linear regression of the serum measure on the mean of the two $24 \mathrm{~h}$ dietary recalls, adjusted for energy intake, BMI, smoking, age and sex; intra $_{x}$ is the intra-person variation for the intake variable; inter $_{x}$ is the inter-person variation for the intake variable; and $n_{x}$ is the number of days of dietary recall, which was two in the present study ${ }^{(39)}$.

\section{Results}

Demographic and anthropometric measurements for this population are shown in Table 1. A total of 352 participants were enrolled in the study, consisting of 225 women (64\%) and $127(36 \%)$ men. The mean age of the study participants was $74.4(\mathrm{sD} 6 \cdot 4)$ years. Male participants were older and most had attended some elementary school. The majority of women were illiterate. Most participants were of rural origin (Table 1). More than 11\% admitted to current tobacco use, and $21 \%$ had previously smoked for more than 1 year. Only $7 \cdot 7 \%$ acknowledged current alcohol consumption; $50 \%$ used to drink occasionally, $10 \%$ most days and only $4 \cdot 6 \%$ daily. A considerable percentage of the participants were overweight or obese. A higher percentage of women were overweight than men (Table 1).

On the basis of the IDF definition, the majority of MetS components were more frequent in women than in men; women had elevated waist circumference $(P<0.05)$, elevated TAG $(P<0 \cdot 001)$ and lower HDL cholesterol than men $(P<0 \cdot 0001 ;$ Table 2$)$. Hypertension and elevated blood glucose concentrations did not differ by sex. Similar results were found using the ATP III criteria (data not shown).

On the basis of IDF criteria, $40 \%$ of participants had MetS. Among these participants, 19\% were men and $81 \%$ were women $\left(\chi^{2}=32 \cdot 6, \quad P<0 \cdot 0001\right)$, whereas $33 \%$ ( $18.3 \%$ men and $81.7 \%$ women) had MetS on the basis of the ATP III definition. In addition, $52 \%(110 / 210)$ of the participants without MetS (defined by IDF) exhibited two or more of its components. In participants without MetS, a higher percentage of women than men exhibited two or more components of MetS (68/110 v. 42/110; $\chi^{2}=9 \cdot 094$, $P=0 \cdot 002)$.

On the basis of serum or plasma concentrations, micronutrient inadequacies were common for men and women, respectively (values in parenthesis are the median and 10th and 90th percentiles followed by the percentage of participants who had low values): vitamin $\mathrm{C}$ $(0 \cdot 17(0 \cdot 02-0 \cdot 44), 0 \cdot 26(0 \cdot 09-0 \cdot 56) \mathrm{mg} / \mathrm{dl} ; 60 \%$ and $33 \%)$, vitamin $\mathrm{B}_{6}(39 \cdot 9$ (23-64), $48 \cdot 1(27 \cdot 3-78 \cdot 3) \mathrm{nmol} / \mathrm{l} ; 27 \%$ and 
Table 1 Demographic characteristics and anthropometric measurements of elderly Ecuadorians

\begin{tabular}{|c|c|c|c|c|c|}
\hline \multirow[b]{2}{*}{ Variables } & \multicolumn{2}{|c|}{ Men ( $n$ 127) } & \multicolumn{2}{|c|}{ Women (n 225) } & \multirow[b]{2}{*}{$P$} \\
\hline & Mean & SD & Mean & SD & \\
\hline Age (years) $\dagger$ & $75 \cdot 8$ & $6 \cdot 5$ & $73 \cdot 7$ & $6 \cdot 1$ & $<0.001$ \\
\hline Education level & & & & & \\
\hline No school (\%) & \multicolumn{2}{|c|}{$29 \cdot 4$} & \multicolumn{2}{|c|}{$52 \cdot 5$} & $<0.0001$ \\
\hline Birth place (\% rural) & \multicolumn{2}{|c|}{$69 \cdot 0$} & \multicolumn{2}{|c|}{$73 \cdot 9$} & NS \\
\hline \multicolumn{6}{|l|}{ Anthropometrics } \\
\hline Weight $(\mathrm{kg})$ & $59 \cdot 9$ & $9 \cdot 5$ & $54 \cdot 0$ & $9 \cdot 8$ & $<0.0001$ \\
\hline Height $(\mathrm{cm})$ & $156 \cdot 0$ & $6 \cdot 7$ & $144 \cdot 0$ & $6 \cdot 0$ & $<0.0001$ \\
\hline Height by knee height $(\mathrm{cm}) \ddagger$ & $158 \cdot 0$ & $6 \cdot 4$ & $144 \cdot 0$ & $5 \cdot 3$ & $<0.0001$ \\
\hline Knee height $(\mathrm{cm})$ & $48 \cdot 0$ & $3 \cdot 5$ & $44 \cdot 5$ & $2 \cdot 8$ & $<0.0001$ \\
\hline Waist circumference $(\mathrm{cm})$ & $87 \cdot 5$ & $9 \cdot 4$ & $87 \cdot 3$ & $11 \cdot 6$ & NS \\
\hline BMI $\left(\mathrm{kg} / \mathrm{m}^{2}\right)$ & $24 \cdot 8$ & $3 \cdot 2$ & $26 \cdot 1$ & $4 \cdot 0$ & $<0.001$ \\
\hline Underweight $\left(<20 \mathrm{~kg} / \mathrm{m}^{2} ; \%\right)$ & \multicolumn{2}{|c|}{$2 \cdot 7$} & \multicolumn{2}{|c|}{$4 \cdot 5$} & NS \\
\hline Normal $\left(20 \cdot 0-24.9 \mathrm{~kg} / \mathrm{m}^{2} ; \%\right)$ & \multicolumn{2}{|c|}{$57 \cdot 3$} & \multicolumn{2}{|c|}{$39 \cdot 8$} & $<0.001$ \\
\hline Overweight $\left(25 \cdot 0-29 \cdot 9 \mathrm{~kg} / \mathrm{m}^{2} ; \%\right)$ & \multicolumn{2}{|c|}{$29 \cdot 5$} & \multicolumn{2}{|c|}{$41 \cdot 2$} & $<0.05$ \\
\hline Obese $\left(\geq 30 \cdot 0 \mathrm{~kg} / \mathrm{m}^{2} ; \%\right)$ & \multicolumn{2}{|c|}{$3 \cdot 3$} & \multicolumn{2}{|c|}{$14 \cdot 0$} & $<0.01$ \\
\hline
\end{tabular}

tRange is 65-94 years for men; 65-97 years for women.

Calculated as described in Blaum et al. ${ }^{(19)}$.

Table 2 Distribution of MetS components in elderly Ecuadorians by IDF definition

\begin{tabular}{|c|c|c|c|c|}
\hline & Total $(n$ 301-352) $\dagger$ & Men $(n$ 111-127) & Women ( $n$ 190-225) & \\
\hline MetS components & $\%$ & $\%$ & $\%$ & $P$ \\
\hline High waist circumference $($ men $>90 \mathrm{~cm}$, women $>80 \mathrm{~cm})$ & 61 & 37 & 75 & $<0.0001$ \\
\hline Blood pressure (systolic $\geq 130 \mathrm{mmHg}$ or diastolic $\geq 85 \mathrm{mmHg}$ ) & 51 & 55 & 49 & NS \\
\hline Fasting glucose ( $\geq 100 \mathrm{mg} / \mathrm{dl})$ & 11 & 9 & 13 & NS \\
\hline TAG $(\geq 150 \mathrm{mg} / \mathrm{dl})$ & 40 & 28 & 46 & $<0.001$ \\
\hline HDL cholesterol (men $<40 \mathrm{mg} / \mathrm{dl}$, women $<50 \mathrm{mg} / \mathrm{dl})$ & 73 & 56 & 83 & $<0.0001$ \\
\hline
\end{tabular}

IDF, International Diabetic Federation; MetS, metabolic syndrome.

tTotal numbers are 352, 301, 351, 351 and 351 for waist circumference, blood pressure, fasting glucose, TAG and HDL cholesterol, respectively.

$16 \%)$, vitamin $\mathrm{B}_{12}(360$ (216-676), $390(208-729) \mathrm{pg} / \mathrm{ml}$ $21 \%$ and $20 \%)$, folate $(5 \cdot 5(3 \cdot 4-8 \cdot 3), 6 \cdot 2(3 \cdot 7-10 \cdot 5) \mathrm{ng} / \mathrm{ml}$ $37 \%$ and $27 \%)$ and zinc (75 (48-106), $71(47-108) \mathrm{ug} / \mathrm{dl}$; 41 and 45\%). Deficiencies of vitamins A (54 (39-72), $50(36-66) \mu \mathrm{g} / \mathrm{dl})$ and $\mathrm{D}($ severe $<10 \mathrm{ng} / \mathrm{ml} ; 22(14-29)$, 19 (12-26) ng/ml), iron (123 (79-188), 107 (62-161) $\mu \mathrm{g} / \mathrm{dl})$ and calcium $(9 \cdot 2(8 \cdot 6-10 \cdot 2), 9 \cdot 3(8 \cdot 6-10) \mathrm{mg} / \mathrm{dl})$ were present in $<15 \%$ of participants. Mild vitamin D deficiency $(<25 \mathrm{ng} / \mathrm{ml})$ was present in $65 \%$ and $87 \%$ of men and women, respectively.

After adjusting for age and sex, plasma vitamin E:TAG ratios and vitamin $\mathrm{C}$ concentrations were inversely associated with MetS $(\mathrm{OR}=0 \cdot 78,95 \% \mathrm{CI} 0 \cdot 71,0 \cdot 86 ; \mathrm{OR}=0 \cdot 16$, 95\% CI 0.03, 0·81, respectively; Table 3 ). High plasma CRP $(>3 \mathrm{mg} / \mathrm{l})$ was present in $48.9 \%$ of the participants and was positively associated with MetS (OR $=1 \cdot 79$, 95\% CI 1·04, 3·06; Table 3). High plasma Hcy $(>15 \mathrm{nmol} / \mathrm{ml})$, or low zinc, copper or B vitamins, was not associated with MetS (Table 3).

After adjusting for age and sex, low plasma vitamin E:TAG ratios were associated with high plasma glucose $(\mathrm{OR}=0 \cdot 74,95 \%$ CI $0 \cdot 63,0 \cdot 86)$, low HDL cholesterol $(\mathrm{OR}=0.84,95 \%$ CI $0.78,0.92)$ and high waist circumference $(\mathrm{OR}=0 \cdot 91,95 \%$ CI $0 \cdot 85,0 \cdot 98)$. Low plasma vitamin $\mathrm{C}$ was also associated with hypertension $(\mathrm{OR}=$
Table 3 Association of age, sex, blood micronutrients, CRP and homocysteine with MetS using the IDF definition

\begin{tabular}{lcc}
\hline Variables & ORt & $95 \% \mathrm{Cl}$ \\
\hline Age (years) & 0.99 & $0.95,1.06$ \\
Sex (male) & $0 \cdot 18$ & $0 \cdot 10,0.40$ \\
Vitamin C $(\mathrm{mg} / \mathrm{dl})$ & $0 \cdot 16$ & $0.03,0.81$ \\
PLP $(\mathrm{nmol} / \mathrm{l})$ & 1.01 & $1.00,1.02$ \\
Vitamin $\mathrm{B}_{12}(\mathrm{pg} / \mathrm{ml})$ & 1.00 & $0.99,1.01$ \\
Folate $(\mathrm{ng} / \mathrm{ml})$ & 1.04 & $0 \cdot 94,1 \cdot 16$ \\
Cu $(\mu \mathrm{g} / \mathrm{dl})$ & 0.99 & $0.98,1.00$ \\
Zn $(\mu \mathrm{g} / \mathrm{dl})$ & 1.00 & $0.99,1.02$ \\
High plasma CRP $(>3 \mathrm{mg} / \mathrm{l})$ & 1.79 & $1.04,3.06$ \\
High plasma homocysteine $(>15 \mathrm{nmol} / \mathrm{ml})$ & 1.73 & $0.94,3.18$ \\
Vitamin E:TAG ratio & 0.78 & $0.71,0.86$
\end{tabular}

CRP, C-reactive protein; PLP, pyridoxal phosphate; MetS, metabolic syndrome; IDF, International Diabetic Federation.

tOR is based on a multiple logistic regression model, adjusting for age and sex.

$0 \cdot 15,95 \%$ CI $0 \cdot 03,0 \cdot 67)$, high waist circumference $(\mathrm{OR}=$ $0 \cdot 15,95 \%$ CI $0 \cdot 03,0 \cdot 68)$ and low HDL cholesterol $(\mathrm{OR}=$ $1 \cdot 94,95 \%$ CI $1 \cdot 07,3 \cdot 50)$.

Analysis of the dietary intake from the participants is shown in Table 4. In general, the diets were of poor quality - high in carbohydrate and sodium $(>50 \%$ had intake higher than recommended) and low in protein (about 23\% had intake below that recommended), fat 
Table 4 Dietary macronutrient and micronutrient intake of elderly Ecuadorians (average of two $24 \mathrm{~h}$ recalls)

Men

\begin{tabular}{|c|c|c|c|c|c|c|c|c|c|}
\hline \multirow[b]{3}{*}{ Nutrients } & \multirow{3}{*}{$\begin{array}{c}\text { AMDRt, } \\
\text { EAR } \neq \text { or Als }\end{array}$} & & \\
\hline & & \multicolumn{2}{|c|}{ Intake (n 218) } & \multirow{2}{*}{$\begin{array}{l}\text { Below } \\
\text { ref. (\%) }\end{array}$} & \multirow{2}{*}{$\begin{array}{l}\text { Above ref. } \\
\text { or UL (\%) }\end{array}$} & \multicolumn{2}{|c|}{ Intake (n 124) } & \multirow{2}{*}{$\begin{array}{l}\text { Below } \\
\text { ref. (\%) }\end{array}$} & \multirow{2}{*}{$\begin{array}{l}\text { Above ref } \\
\text { or UL }(\%)\end{array}$} \\
\hline & & Mean & Range & & & Mean & Range & & \\
\hline Energy (kcal)\| & & 1187 & $327-2805$ & & & 1159 & $166-2428$ & & \\
\hline Fat (\% energy) & $20-35+$ & $21 \cdot 9$ & $5 \cdot 3-53 \cdot 6$ & $41 \cdot 2$ & $5 \cdot 1$ & $21 \cdot 9$ & $6 \cdot 0-40 \cdot 6$ & $44 \cdot 4$ & 0.8 \\
\hline Carbohydrate (\% energy) & $45-65 t$ & $65 \cdot 8$ & $10 \cdot 3-87 \cdot 6$ & $2 \cdot 3$ & $55 \cdot 5$ & 65.9 & $36 \cdot 0-88 \cdot 8$ & 0.8 & $55 \cdot 7$ \\
\hline Protein (\% energy) & $10-35+$ & $13 \cdot 2$ & $5 \cdot 3-33 \cdot 9$ & $20 \cdot 6$ & 0.0 & $13 \cdot 0$ & $5 \cdot 7-25 \cdot 9$ & $27 \cdot 4$ & 0.0 \\
\hline Total vitamin A ( $\mu \mathrm{g}$ RAE) & $500-6252$ & 396 & $0 \cdot 2-3588$ & $74 \cdot 3$ & $0 \cdot 0$ & 429 & $1 \cdot 7-2696$ & $78 \cdot 2$ & $0 \cdot 0$ \\
\hline Vitamin D ( $\mu \mathrm{g}$ calciferol) & $15 \S$ & $1 \cdot 35$ & $0.00-7.57$ & $100 \cdot 0$ & 0.0 & 1.53 & $0.00-11.0$ & $100 \cdot 0$ & 0.0 \\
\hline$\alpha$-Tocopherol (mg) & $12 \ddagger$ & $3 \cdot 10$ & $0.35-8 \cdot 47$ & $100 \cdot 0$ & $0 \cdot 0$ & $3 \cdot 24$ & $0.21-8 \cdot 78$ & $100 \cdot 0$ & $0 \cdot 0$ \\
\hline Vitamin K ( $\mu$ g phylloquinone) & $90-120 \S$ & $29 \cdot 4$ & $1 \cdot 0-429$ & $95 \cdot 4$ & & $26 \cdot 1$ & $1 \cdot 2-283$ & $97 \cdot 6$ & \\
\hline Vitamin $\mathrm{C}(\mathrm{mg})$ & $60-75$ & $50 \cdot 3$ & $0 \cdot 2-390$ & $74 \cdot 8$ & 0.0 & $49 \cdot 88$ & $1 \cdot 0-394$ & $84 \cdot 7$ & 0.0 \\
\hline Riboflavin (mg) & $0 \cdot 9-1 \cdot 1 \ddagger$ & 0.85 & $0 \cdot 06-2 \cdot 61$ & $64 \cdot 2$ & & 0.89 & $0 \cdot 13-2 \cdot 49$ & $70 \cdot 2$ & \\
\hline Folate $(\mu \mathrm{g})$ & $320 \neq$ & 208 & $0-646$ & $82 \cdot 1$ & $0 \cdot 0$ & 227 & $18 \cdot 7-743$ & $76 \cdot 6$ & 0.0 \\
\hline Vitamin $B_{6}(\mathrm{mg})$ & $1 \cdot 3-1 \cdot 4 \ddagger$ & $1 \cdot 24$ & $0.21-4.59$ & $58 \cdot 3$ & 0.0 & $1 \cdot 25$ & $0 \cdot 10-2 \cdot 80$ & 62.9 & 0.0 \\
\hline Vitamin $B_{12}(\mu \mathrm{g})$ & $2 \cdot 0 \ddagger$ & $2 \cdot 60$ & $0 \cdot 00-19 \cdot 0$ & $56 \cdot 0$ & & 3.02 & $0 \cdot 0-18 \cdot 2$ & $54 \cdot 8$ & \\
\hline $\mathrm{Ca}(\mathrm{mg})$ & $1200 \$$ & $247 \cdot 00$ & $21 \cdot 3-908$ & $100 \cdot 0$ & $0 \cdot 0$ & 248 & $30-928$ & $100 \cdot 0$ & $0 \cdot 0$ \\
\hline$P(m q)$ & $580 \pm$ & 575.00 & $77-1470$ & $58 \cdot 3$ & 0.0 & 605 & $121-1364$ & $52 \cdot 4$ & 0.0 \\
\hline $\mathrm{Mg}(\mathrm{mg})$ & $265-350 \ddagger$ & $160 \cdot 00$ & $13-432$ & 93.6 & $1 \cdot 4$ & 167 & $23-415$ & $99 \cdot 2$ & 0.8 \\
\hline $\mathrm{Fe}(\mathrm{mg})$ & $5 \cdot 0-6 \cdot 0 \ddagger$ & $6 \cdot 29$ & $0 \cdot 02-17 \cdot 6$ & 39.5 & 0.0 & $6 \cdot 76$ & $1 \cdot 37-22 \cdot 0$ & $50 \cdot 0$ & $0 \cdot 0$ \\
\hline $\mathrm{Zn}(\mathrm{mg})$ & $6 \cdot 8-9 \cdot 4 \ddagger$ & $5 \cdot 30$ & $0.63-16.8$ & 73.9 & 0.0 & $5 \cdot 59$ & $0.75-13.1$ & $92 \cdot 7$ & 0.0 \\
\hline $\mathrm{Cu}(\mu \mathrm{g})$ & $700 \ddagger$ & 862 & $50-4005$ & $38 \cdot 1$ & 0.0 & 886 & $110-4150$ & $34 \cdot 7$ & 0.0 \\
\hline Se $(\mu \mathrm{g})$ & $45 \ddagger$ & $64 \cdot 20$ & $7 \cdot 8-210$ & $28 \cdot 0$ & $0 \cdot 0$ & $68 \cdot 6$ & $12 \cdot 0-218$ & $27 \cdot 4$ & 0.0 \\
\hline $\mathrm{K}(\mathrm{mg})$ & $4700 \$$ & 1651 & $134-4036$ & $100 \cdot 0$ & 0.0 & 1659 & $184-3820$ & $100 \cdot 0$ & 0.0 \\
\hline $\mathrm{Na}(\mathrm{mg})$ & $1200 \S$ UL 2300 & 3094 & 69-20342 & $15 \cdot 6$ & $53 \cdot 1$ & 3287 & $200-13255$ & $13 \cdot 7$ & $62 \cdot 1$ \\
\hline
\end{tabular}

AMDR, Acceptable Macronutrient Distribution Range; EAR, Estimated Average Requirement; AI, Adequate Intake; ref., reference; UL, Upper Limit; RAE, retinol activity equivalents.

†EAR for women-men aged $>70$ years ${ }^{(51,52)}$.

\$Al for women-men aged $>70$ years; EAR not available ${ }^{(52-56)}$.

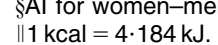


Table 5 Correlation between dietary and blood nutrient concentrations

\begin{tabular}{|c|c|c|c|}
\hline Dietary variable & Serum variable & $\begin{array}{c}\text { Observed regression } \\
\text { coefficient }\end{array}$ & $\begin{array}{c}\text { Corrected regression } \\
\text { coefficientt }\end{array}$ \\
\hline Vitamin C (mg) & Vitamin C (mg/dl) & $0 \cdot 0005^{\star}$ & 0.001 \\
\hline Vitamin $B_{12}(\mu \mathrm{g})$ & Vitamin $B_{12}(p g / m l)$ & $9 \cdot 0$ & $21 \cdot 70$ \\
\hline $\mathrm{Zn}(\mathrm{mg})$ & $\mathrm{Zn}(\mu \mathrm{g} / \mathrm{dl})$ & $0 \cdot 19$ & 0.40 \\
\hline FV servings & PLP (nmol/l) & $1 \cdot 6^{*}$ & $3 \cdot 40$ \\
\hline FV servings & Vitamin C $(\mu \mathrm{g} / \mathrm{dl})$ & $0.02^{*}$ & 0.04 \\
\hline Animal protein (g) & $\mathrm{Zn}(\mu \mathrm{g} / \mathrm{dl})$ & 0.01 & 0.02 \\
\hline Animal protein $(\mathrm{g})$ & Vitamin $B_{12}(p g / m l)$ & $2 \cdot 4^{\star}$ & $5 \cdot 70$ \\
\hline
\end{tabular}

PLP, pyridoxal phosphate; FV, fruit and vegetables.

${ }^{\star} P<0.05$ adjusted for age, sex, smoking, BMI and energy intake.

tAlso adjusted for intra- or inter-individual variation in dietary intake.

(about $42 \%$ had intake below that recommended) and several micronutrients (see Table 4), consistent with the low blood micronutrient status exhibited.

The main sources of energy were white rice (16\%), potatoes (13\%), sugar ( $8 \%$ ) and bread (7.5\%). Milk, eggs, cheese, beef, chicken giblet and chicken breast contributed $4 \cdot 5 \%, 1 \%, 0 \cdot 6 \%, 3 \cdot 7 \%$ and $2 \cdot 6 \%$, respectively. Intakes of grains other than rice and wheat (barley, oats, $2 \cdot 3 \%$ of energy), legumes (mainly black beans, $0 \cdot 7 \%$ ), vegetables other than potato (corn, onions, cassava, plantains, total $4.5 \%$ ) and of fruit (mainly banana, $0 \cdot 6 \%$ ) were low. Protein consumption was low and was derived mainly from beef (11\%), rice (9\%), chicken giblet (9\%), milk $(7 \%)$ and potatoes (7\%). Fish provided $3 \%$ of the protein. The main source of fat was from palm oil (16\%); the main sources of carbohydrate were rice (20\%), potatoes (16\%) and white sugar (13\%).

Glycaemic load (GL) was mainly from white rice (25\%), potatoes $(21 \%)$, white granulated sugar (12.5\%), bread $(9 \cdot 7 \%)$ and pasta $(2 \cdot 7 \%)$. The diet of $20 \%$ of participants was of high GI, using glucose as the reference $^{(40)}$. Based on the percentage of total energy intake, according to the Acceptable Macronutrient Distribution Range $^{(41)}, 93 \%$ of the participants consumed low linoleic and $\alpha$-linolenic acid. However, there was no correlation between high GI, GL or low unsaturated fat with MetS (data not shown) in this population. Sodium intake was mainly from regular salt (76\%), boiled potato $(4 \cdot 4 \%)$ and bread $(4 \cdot 3 \%)$. The average intake of dietary salt was $3 \cdot 2 \mathrm{~g}$. As indicated above, the consumption of fruit and vegetables and animal products was low, and most likely contributing to low serum micronutrient status, as indicated by positive correlations between the intake of fruit and vegetables and plasma vitamin $\mathrm{C}$, vitamin $\mathrm{B}_{6}$ and folate concentrations $(P<0 \cdot 05$; Table 5$)$. A significant correlation between plasma vitamin $\mathrm{B}_{12}$ and animal products in the diet was also observed $(P<0 \cdot 05$; Table 5$)$. We observed positive correlations between dietary intakes of vitamin $C$, vitamin $\mathrm{B}_{6}$, PLP and zinc with respective plasma concentrations, but these reached statistical significance for vitamin $\mathrm{C}$ only $(P<0 \cdot 05$; Table 5$)$. The lack of statistically significant association between the dietary and blood levels of these nutrients could be due to high day-to-day variation in dietary intake, as indicated by substantially higher regression coefficients after adjustment for intra- or inter-individual variation (Table 5). A larger number of dietary recalls might be needed to obtain accurate dietary intake for these nutrients.

\section{Discussion}

We report that MetS, a constellation of conditions associated with substantial morbidity and mortality worldwide, is prevalent ( $40 \%$ and $33 \%$, respectively, using the IDF and ATP III definitions) among the poor elderly Ecuadorians living in Quito, Ecuador. This prevalence is comparable to that reported for elderly adults living in the USA $(40 \%)^{(5)}$. Similar to observations in the USA, prevalence is higher among women than men. Furthermore, a significant proportion of elderly participants without MetS had two of the MetS components. Despite their low socio-economic status, 33\% of elderly men and $55 \%$ of elderly women were overweight. A significant proportion of these adults exhibited low concentrations of blood micronutrients (15\%, 82\%, 15\%, 20\%, 29\% and $37 \%$ had vitamins $\mathrm{D}, \mathrm{C}, \mathrm{B}_{6}, \mathrm{~B}_{12}$, folate and zinc inadequacy, respectively, and $88 \%$ exhibited at least one vitamin or mineral deficiency), indicating that they suffer from the increasingly common double burden of malnutrition and chronic disease associated with food insecurity and nutrition transition in less developed countries. Although historically malnutrition was defined as undernutrition, in recent years a situation has been described that links poverty, food insecurity and malnutrition to obesity and associated diseases ${ }^{(42)}$. This paradoxical condition has been attributed to the fact that the diet of most of the world's poor consists of 'empty energy', i.e. a diet of poor quality. This diet is low in essential nutrients, resulting in the coexistence of both over- and undernutrition in those 
living in poverty. The absence of a diversified nutrientdense diet can lead to energy overnutrition and obesity as well as micronutrient deficiencies. Related to this, households characterized as food-insecure have been shown to have the highest $\mathrm{BMI}^{(43)}$. In fact, the analysis of dietary intake of the participants in the present study supports the contribution of poor-quality diet in this population to the prevalence of under- and overnutrition in the Ecuadorian elderly. Our results show, for the first time, the existence of this paradoxical condition in elderly Ecuadorians. These findings may be relevant to $30 \%$ of the elderly in Ecuador who live in the Andean region, and to the elderly of other developing Latin American countries living in similar conditions.

There was a $12 \%$ difference in MetS prevalence using the IDF or ATP III definitions. This appears to be due to the lower cut-off points for waist circumference used in the IDF definition. Among MetS components, low HDL cholesterol, high waist circumference and hypertension were present in $>50 \%$ of the participants, while high fasting glucose concentrations were only observed in $11 \%$. We present most of our results using the worldwide IDF MetS consensus statement definition ${ }^{(23)}$. This definition uses South Asian recommendations for waist circumference, which may be more appropriate for this population than those used in APT III. No cut-off points are presently available for Central and South Americans. More research is needed to determine the most appropriate cut-off points for this important indicator in different populations.

Although the aetiological pathways that lead to MetS have not been fully determined ${ }^{(6)}$, it is clear that nutritional status and intake are important contributors ${ }^{(12)}$. Limited evidence suggests that circulating concentrations of antioxidants may be lower among people with MetS than those without this condition ${ }^{(44)}$. Furthermore, low vitamin $\mathrm{B}$ concentrations and high $\mathrm{Hcy}^{(45,46)}$ and $\mathrm{CRP}^{(8,47)}$ have been associated with MetS. We found high prevalences of low blood concentrations of vitamins $\mathrm{C}$, $\mathrm{B}_{6}, \mathrm{~B}_{12}$, folate and zinc and elevated CRP and Hcy concentrations in this population. However, only plasma vitamin $\mathrm{C}$, vitamin $\mathrm{E}$ and CRP were significantly associated with MetS in this relatively small sample. As MetS appears to be linked to oxidative stress ${ }^{(48)}$, it is plausible that deficiencies of micronutrients with antioxidant properties, including vitamins $\mathrm{C}$ and $\mathrm{E}$, could be related to MetS, although, given the cross-sectional design of the study, it is not possible to draw conclusions on the potential pathogenic mechanisms of those deficiencies. Vitamin C deficiency was the most commonly identified deficiency in our participants. Low plasma vitamin C may reflect low fruit and vegetable intake, which has been shown to increase the risk of $\mathrm{Met}^{(8,49)}$. In support of this, fruit and vegetable servings correlated negatively with high systolic BP, although this did not reach statistical significance.
Dietary analysis showed that, as a group, these elderly individuals consumed diets of poor quality, with the majority consuming higher than recommended levels of carbohydrates, mostly of high or intermediate GI, and lower than recommended levels of fat, especially polyunsaturated fat, and micronutrients, consistent with the observed low BP status seen for several micronutrients. More than $50 \%$ of these older adults had hypertension, which may be related to the high daily sodium intake and/or prevalence of vitamin C deficiency. Although we observed a significant association between serum vitamin $\mathrm{C}$ concentration and hypertension, the association between dietary sodium intake and BP did not reach statistical significance. This may reflect the difficulty in obtaining accurate dietary sodium intake. We found a strong inverse correlation between vitamin $\mathrm{E}$ concentrations and risk of MetS. The underlying mechanisms for the apparent protective effect of vitamin $\mathrm{E}$ need to be determined and may differ from those of vitamin $\mathrm{C}$, as they were associated with different sets of MetS components (BP for vitamin C; and HDL cholesterol, waist circumference and glucose for vitamin E).

Inflammation, and in particular high CRP concentration, has been implicated in MetS ${ }^{(47)}$. More than $48 \%$ of the elderly in the present study had high CRP concentrations. Inflammatory mechanisms may modulate the nutritional, metabolic and other factors contributing to MetS.

There are limitations to the present study that should be noted. First, this was a cross-sectional study, and as such cannot determine causality. Whether the micronutrient status, particularly that of vitamins $\mathrm{C}$ and $\mathrm{E}$, is causally related to the high prevalence of MetS needs to be further determined. Second, the study population included only the poor elderly Ecuadorians living in periurban, low-income communities. Although this population may be representative of the elderly in other Andean countries such as Bolivia and Peru, the results may not be generalizable to those in coastal areas or those who live in better socio-economic conditions.

In conclusion, MetS is highly prevalent in these poor peri-urban elderly Ecuadorians. Our findings suggest that poor nutritional status is an important contributor to the high prevalence of MetS in this population. As MetS is highly correlated with morbidity and mortality from chronic diseases such as diabetes and CVD, and relatively few resources are available for the health care of elders in Latin American countries, measures to prevent MetS may reduce the burden of these diseases and improve the quality of life in this growing segment of the population. Given the high prevalence of micronutrient deficiencies in the presence of obesity, nutrition interventions could have a significant impact on health outcomes in this population. More research is needed to determine causal factors, but these data suggest that elderly Ecuadorians would benefit from dietary interventions to normalize blood lipids, reduce hypertension and weight gain and 
improve micronutrient status. Given that the diet of these elderly appeared to be high in salt and low in fruit and vegetables, good-quality protein and essential fatty acids, this population is likely to benefit from reduced salt intake, higher consumption of fruit and vegetables, foods with better-quality protein and fatty acid profiles such as fish, chicken, low-fat dairy and legumes.

\section{Acknowledgements}

The present study was supported by grants from the US National Institutes of Health (Fogarty International Center R03 TW005779; the National Institute of Aging, 2R01 AG009140; and the National Institute of Child Health and Development R01 HD38327); and the US Department of Agriculture cooperative agreement no. 58-1950-7-707. Any opinions, findings, conclusions or recommendations expressed in this publication are those of the authors and do not necessarily reflect the view of the US Department of Agriculture. No conflict of interest exists between any of the authors or contributors to the study. F.S. contributed to the design of the study, organization of the study team, preparation of the informed consent, supervision of the enrolment, general supervision of the study and preparation of the entire manuscript; B.E. contributed to the design of the study, standardization of the study team in all measurements, database preparation, analysis of the data and preparation of the entire manuscript; K.L.T. contributed to the analysis, design and interpretation, guidance for field data collection and editing of the final manuscript; D.H.H. contributed to the development of the study design, initial training of data collectors and pilot testing of the data collection instruments, data analysis and assisted with the writing and editing of the manuscript; X.N. contributed to the clinical examination, D.T.H. to application and reading and to the preparation of the manuscript; M.S. contributed to the enrolment and anthropometric measurements, CRONOS application and to the preparation of the manuscript; J.K.G. contributed to the design of the study and review of the manuscript; S.E.N. contributed to the review of the literature and to the Introduction and Methods section of the manuscript, besides assisting in the editing of the Results and Conclusion sections; G.E.D. contributed to the analysis and interpretation of the data, and critically reviewed the manuscript; J.S. contributed to the analysis of the samples and review of the manuscript; S.N.M. contributed to the design of the study, obtained funds to conduct the study, developed the questionnaires and data collection form and conducted the overall supervision of the study with F.S., besides helping with data analysis, data interpretation and manuscript preparation. The Nutritional Evaluation Laboratory of HNRCA conducted the biochemical analysis and outside colleagues Dr Hooman Poor and Dr Jatin Roper helped with field data collection. Alicia Rodriguez and Monica Sanaicela applied the dietary recall.

\section{References}

1. Population Division (2002) UN World Population Ageing 1950-2050. New York: United Nations.

2. Hoskins I, Kalache A \& Mende S (2005) Toward primary health care adapted to elderly people. Pan Am J Public Health 17, 444-451.

3. United Nations (2009) World Population Prospects: the 2008 revision population database. http://esa.un.org/unpp

4. McCarthy M (2004) Boom in Latin American and Caribbean elderly population. Region's health systems have 10 years to prepare for rising number of elderly, report warns. Lancet 363, 458-459.

5. Ford E (2005) Risks for all-cause mortality, cardiovascular disease, and diabetes associated with the metabolic syndrome: a summary of the evidence. Diabetes Care $\mathbf{2 8}$, 1769-1778.

6. Lidfeldt J, Nyberg P, Nerbrand C et al. (2003) Sociodemographic and psychosocial factors are associated with features of the metabolic syndrome. The Women's Health in the Lund Area (WHILA) study. Diabetes Obes Metab 5 , 106-112.

7. McKeown NM, Melgs JB, Liu S et al. (2004) Carbohydrate nutrition, insulin resistance, and the prevalence of the metabolic syndrome in the Framingham offspring cohort. Diabetes Care 27, 538-546.

8. Esmaillzadeh A, Kimiagar M, Mehrabi Y et al. (2006) Fruit and vegetable intakes, C-reactive protein, and the metabolic syndrome. Am J Clin Nutr 84, 1489-1497.

9. Vessby B, Uusitupa M, Hermansen K et al. (2001) Substituting dietary saturated for monounsaturated fat impairs insulin sensitivity in healthy men and women: the KANWU study. Diabetologia 44, 312-319.

10. Bjorklund K, Lind L, Vessy B et al. (2002) Different metabolic predictors of white-coat and sustained hypertension over 20-year follow-up period: a population-based study of elderly man. Circulation 106, 63-68.

11. Ford ES, Mokdad AH, Giles WH et al. (2003) The metabolic syndrome and antioxidant concentrations: findings from the Third National Health and Nutrition Examination Survey. Diabetes 52, 2346-2352.

12. Feldeisen SE \& Tucker KL (2007) Nutritional strategies in the prevention and treatment of metabolic syndrome. Appl Physiol Nutr Metab 32, 46-60.

13. Vari I, Balkau B, Kettaneh A et al. (2007) Ferritin and transferrin are associated with metabolic syndrome abnormalities and their change over time in a general population: Data from an Epidemiological Study on the Insulin Resistance Syndrome (DESIR). Diabetes Care 30, 1798-1801.

14. Sempertegui F, Estrella B, Elmieh N et al. (2006) Nutritional, immunological and health status of the elderly population living in poor neighbourhoods of Quito, Ecuador. $\mathrm{BrJ}$ Nutr 96, 845-853.

15. Instituto Nacional de Estadisticas y Censos (2001) Censo de Población y Vivienda de 2001. Quito: INEC.

16. Szmitko PE, Wang C, Weisel RD et al. (2003) New markers of inflammation and endothelial cell activation. Part I. Circulation 108, 1917-1923.

17. Humphrey LL, Fu R, Rogers $\mathrm{K}$ et al. (2008) Homocysteine level and coronary heart disease incidence: a systematic review and meta-analysis. Mayo Clin Proc $\mathbf{8 3}$, 1203-1212.

18. Gross R (1997) CRONOS (cross-cultural research on the nutrition of older subjects). Food Nutr Bull 18, 267-303.

19. Blaum CS, Fries BE \& Fiatarone MA (1995) Factors associated with low body mass and weight loss in nursing home residents. J Gerontol 50A, M152-M168.

20. Garrow JS \& Webster J (1985) Quetelet's Index $\left(\mathrm{W} / \mathrm{H}^{2}\right)$ as a measure of fatness. Int J Obes 9, 147-153. 
21. Alberti KG, Zimmet P \& Shaw J (2006) Metabloic syndrome - a new world-wide definition. A consensus statement from the International Diabetes Federation. Diabetic Med 23, 469-480.

22. Grundy S, Brewer H, Cleeman J et al. (2004) Definition of metabolic syndrome: report of the National Heart, Lung, and Blood Institute/American Heart Association Conference on Scientific Issues Related to Definition. Circulation 109, 433-438.

23. Meydani SN, Meydani M, Rall LC et al. (1994) Assessment of the safety of high-dose, short-term supplementation with vitamin $\mathrm{E}$ in healthy older adults. Am J Clin Nutr 60, 704-709.

24. Araki A \& Sako Y (1987) Determination of free and total homocysteine in human plasma by high-performance liquid chromatography with fluorescence detection. J Chromatogr 422, 43-52.

25. Selhub J, Jacques PF, Wilson PW et al. (1993) Vitamin status and intake as primary determinants of homocysteinemia in an elderly population. JAMA 270, 2693-2698.

26. Pearson T, Mensah G, Alexander R et al. (2003) Markers of inflammation and cardiovascular disease: application to clinical and public health practice: a statement for healthcare professionals from the Centers for Disease Control and Prevention and the American Heart Association. Circulation 107, 499-511.

27. Tietz N (1995) Clinical Guide to Laboratory Tests. Philadelphia, PA: Harcourt Brace Company.

28. Westgard J, Barry P, Hunt $\mathrm{M}$ et al. (1981) A multi-rule Shewhart chart for quality control in clinical chemistry. Clin Chem 27, 493-501.

29. Expert Panel on Detection, Evaluation and Treatment of High Blood Cholesterol in Adults (2001) Executive summary of the second report of the Third Report of the National Cholesterol Education Program (NCEP) Expert Panel on Detection, Evaluation, and Treatment of High Blood Cholesterol in Adults (Adult Treatment Panel III). JAMA 285, 2486-2497.

30. Burtis C, Ashwood E \& Bruns D (2006) Tietz Textbook of Clinical Chemistry and Molecular Diagnostics, 4th ed. St Louis, MO: Elsevier Saunders.

31. Driskell JA (1994) Vitamin B6 requirements of humans. Nutr Res 14, 293-324.

32. Bailey AL, Maisey S, Southon S et al. (1997) Relationships between micronutrient intake and biochemical indicators of nutrient adequacy in a 'free-living' elderly UK population. Br J Nutr 77, 225-242.

33. Tucker KL, Rich S, Rosenberg I et al. (2000) Plasma vitamin B-12 concentrations relate to intake source in the Framingham offspring study. Am J Clin Nutr 71, 514-522.

34. Sauberilich HE (1990) Evaluation of Folate Nutrition in Population Groups. New York: Wiley and Sons.

35. Cecil R, Goldman L \& Bennett J (2000) Cecil Textbook of Medicine (2 vols), 21st ed. Philadelphia, PA: W.B. Saunders.

36. Zamora RM \& Valverde V (1983) The dietary score as a simplified methodology in processing and analyzing food consumption data. Arch Latinoam Nutr 33, 843-860.

37. US Department of Agriculture, Agricultural Research Service (2004) USDA National Nutrient Database for Standard Reference, Release 17. Beltsville, MD: Nutrient Data Laboratory; available at http://www.nal.usda.gov/ fnic/foodcomp

38. Instituto Nacional de Nutrición, Ministerio de Previsión Social y Sanidad (1965) Tabla de composición de los alimentos ecuatorianos. Quito: Ministerio de Previsión Social y Sanidad.
39. Willett W (1998) Nutritional Epidemiology, 2nd ed., pp. 306-308. New York: Oxford University Press.

40. Flood A, Subar AF, Hull SG et al. (2006) Methodology for adding glycemic load values to the national cancer institute questionnaire database. J Am Diet Assoc 106, 393-402.

41. Food and Nutrition Board (2005) Dietary Reference Intakes for Energy, Carbohydrate, Fiber, Fatty Acids, Cholesterol, Protein, and Amino Acids (Macronutrients), pp. 769-770. Washington, DC: The National Academies Press.

42. Tanumihardjo S, Anderson C, Kaufer-Horwitz M et al. (2007) Poverty, obesity, and malnutrition: an international perspective recognizing the paradox. J Am Diet Assoc 107, 1966-1972.

43. Olson C (1999) Nutrition and health outcomes associated with food insecurity and hunger. J Nutr 129, Suppl. 2, S521-S524.

44. Ford ES (2006) Intake and circulating concentrations of antioxidants in metabolic syndrome. Curr Atheroscler Rep 8, 448-452.

45. Cankurtaran M, Kay T, Yavuz B et al. (2006) Serum vitaminE levels and its relation to clinical features in nonalcoholic fatty liver disease with elevated ALT levels. Acta Gastroenterol Belg 69, 5-11.

46. Meigs J, Jacques P, Selhub J et al. (2001) Fasting plasma homocysteine levels in the insulin resistance syndrome: the Framingham offspring study. Diabetes Care 24, 1403-1410.

47. Yudkin J, Stehouwer C, Emeis J et al. (1999) C-reactive protein in healthy subjects: associations with obesity, insulin resistance, and endothelial dysfunction: a potential role for cytokines originating from adipose tissue? Arterioscler Thromb Vasc Biol 19, 972-978.

48. Nicolson G (2007) Metabolic syndrome and mitochondrial function: molecular replacement and antioxidant supplements to prevent membrane peroxidation and restore mitochondrial function. $J$ Cell Biochem 100, 1352-1369.

49. Yoo S, Nicklas T, Baranowski T et al. (2004) Comparison of dietary intakes associated with metabolic syndrome risk factors in young adults: the Bogalusa Heart Study. Am J Clin Nutr 80, 841-848.

50. Food and Nutrition Board, Institute of Medicine (2002) Dietary reference intakes for energy, carbohydrate, fiber, fat, fatty acids, cholesterol, protein, and amino acids (macronutrients). http://www.nap.edu/catalog/10490.html

51. Food and Nutrition Board, Institute of Medicine (2000) Dietary reference intakes for vitamin A, vitamin K, arsenic, boron, chromium, Copper, iodine, iron, manganese, molybdenum, nickel, silicon, vanadium, and zinc. http:// www.nap.edu/catalog/10026.html

52. Institute of Medicine (2000) Dietary reference intakes: applications in dietary assessment. http://books.nap.edu/ catalog/9956.html

53. Food and Nutrition Board, Institute of Medicine (2004) Dietary reference intakes for water, potassium, sodium, chloride, and sulfate. http://www.nap.edu/catalog/ 10925.html

54. Institute of Medicine (1997) Dietary reference intakes for calcium, phosphorus, magnesium, vitamin $\mathrm{D}$, and fluoride. http://www.nap.edu/books/0309063507/html/

55. Institute of Medicine (1998) Dietary reference intakes for thiamin, riboflavin, niacin, vitamin B6, folate, Vitamin B12, pantothenic acid, biotin, and choline. http://www.nap.edu/ catalog/6015.html

56. Institute of Medicine (2000) Dietary reference intakes for vitamin C, vitamin E, selenium, and carotenoids. http:// www.nap.edu/catalog/9810.html 